Review

\title{
A Review on the Application of the MPC Technology in Wind Power Control of Wind Farms
}

\author{
Chenchang $\mathrm{Li}^{1}$, Jianqiang $\mathrm{Hu}{ }^{1,}{ }^{*}$, Jie $\mathrm{Yu}^{2}$, Jieci Xue ${ }^{1}$, Runze Yang ${ }^{3}$, Yijie Fu ${ }^{1}$, Bo Sun ${ }^{4}$
}

1. Jiangsu Provincial Key Laboratory of Networked Collective Intelligence and School of Mathematics, Southeast University, Nanjing 211189, China; E-Mails: Icc62522@163.com; jghu@seu.edu.cn; a6487500412@163.com; fuyijie525@163.com

2. School of Electrical Engineering, Southeast University, Nanjing 210096, China; E-Mail: yujie@seu.edu.cn

3. School of Computer Science and Engineering, Southeast University, Nanjing 210096, China; EMail:yrz0323@163.com

4. School of Cyber Science and Engineering, Southeast University, Nanjing 210096, China; E-Mail: 1415234361@qq.com

* Correspondence: Jianqiang Hu; E-Mail: jqhu@seu.edu.cn

Academic Editor: Andrés Elías Feijóo Lorenzo

Collection: Wind Energy

Journal of Energy and Power Technology

2021, volume 3 , issue 3

doi:10.21926/jept.2103033
Received: April 23, 2021

Accepted: June 24, 2021

Published: July 15, 2021

\begin{abstract}
Due to the uncertainty and volatility of wind speed, its natural output power also exhibits strong volatility. In order to avoid the negative effects of the excessive fluctuation of the output power of wind turbines in the wind farm and the power grid, it is very important to accurately predict and reasonably plan and control the output power of the wind farm. Model predictive control (MPC) is a type of advanced control method that can deal with a multi-input multi-output nonlinear system. Compared to the traditional proportional integral derivative control, MPC is more suitable for the complex wind farm model and exhibits good control performance, and has been gradually applied to control the wind power in wind farms. In this article, we have summarized the application of the MPC technology in the prediction and control of wind power in a wind farm, analyze the application of the MPC technology,
\end{abstract}

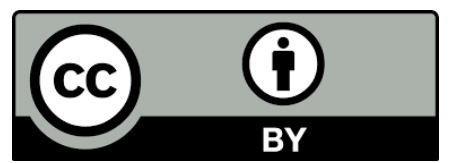


including MPC, multi-objective MPC, nonlinear MPC, and distributed MPC, in the wind farm power control with different optimization objectives. In addition, the optimization of the active and reactive power of wind farms has also been discussed in detail. Furthermore, some hot topics in the current research, such as the multi-objective optimization problem of coordinating the maximum power and reducing the fatigue load and power smoothing control problem, have been summarized. Finally, the existing problems of MPC applied to wind power systems have been discussed.

\section{Keywords}

Model predictive control; wind power generation; active and reactive power control; wind power optimal dispatching

\section{Introduction}

Wind energy is a type of clean, renewable resource with abundant reserves. After the outbreak of the world oil crisis in the 1970s, a few developed countries in the European and American continents devoted great efforts to developing modern wind turbines to replace fossil fuels. Owing to several decades of continuous innovation in wind power technology, the scale of global wind power has been expanding, and its cost and reliability are close to the traditional method of thermal power generation. Although China's wind power market started behind the developed countries, its speed of development is very fast. By the end of 2020, China's cumulative wind power installed capacity was up to $281 \mathrm{GW}$, which accounts for near $40 \%$ of the world's total installed capacity. In the near future, the diversity of wind power development scenarios in China will increase continuously. Thus, the cost of wind power will be further reduced, and the integration and transformation of wind power operation and cross-industry technology will enter an active period.

Wind power generation has been already occupying an increasing share rate in the power grid. However, due to the uncertainty of wind energy, the random fluctuation of wind power results in the power imbalance of the system and affects the frequency stability of the power grid. Modern wind power generation systems require higher controllability, especially the ability to regulate active and reactive power. For a wind turbine control level, a slow control level (power controller) and a fast control level (frequency converter-rotor current controller) exist in the control loop. Hansen et al. [1] and Mei et.al [2], consider the division of the control of active and reactive power. Based on neural networks and power prediction, Jafarnejadsani et al. [3] and Ebrahimi et al. [4] proposed an optimization strategy of wind power control. In Bahadur et al.'s work [5], the pitch angle was controlled by a proportional-integral (PI) control method to reduce the fluctuation of the rotor speed and the pitch angle, but the response speed of the pitch angle control was observed to be slow. In Luo et al.'s work [6], the coordination of the pitch angle control and the rotor speed control was proposed for preventing the rotor speed from reaching the upper limit prematurely and changing the extracted mechanical energy, and exploiting the kinetic inertia together to regulate the active power. For the wind farm control level, in combination with various control techniques, a considerable amount of attention has been paid to the overall power control in wind farms. In the case of wind power fluctuation and inaccurate system model, the authors Sánchez et al. in [7] utilized the model predictive control (MPC) technology to test the control ability of reactive power 
of a voltage source converter high-voltage direct current network. In Wu et al.'s work [8], the reactive power control of a wind farm was realized via several switchable and variable reactors and transformers to coordinate the control voltage. For large wind farms, distributed MPC was used in Liu et al.'s work [9] to realize the coordination and optimization between the thermal plant, the hydro plant, and the wind farm in order to realize load frequency control. With the increase in the wind power scale, increasing amount of attention is being paid to the fatigue of wind turbines. In Ref. [10-13], the concepts of wind turbine tower fatigue under wind load, seismic response of wind turbines, and wave loads on offshore wind turbines have been discussed in detail. In Yao et al.'s work [14], the active power control of a two-degrees-of-freedom wind turbine (which simultaneously controls the rotor speed and the pitch angle) based on the small signal method was investigated and was found to significantly reduce the torque fatigue of the wind turbine tower.

In the current wind power control systems of wind farms, the traditional proportional integral derivative (PID) control still remains the mainstream control technique and is widely employed due to its simplicity and quick response. However, the disadvantages of PID control have gradually emerged owing to the demand for higher wind power control quality, for coping with the complex coupled structure of the control system, or for determining the optimal PID coefficients. On the contrary, In Wang et al.'s work [15], the MPC strategy is capable of coping with these emerging problems by solving the optimal control inputs in each time period. Compared to the PID control, MPC exhibits better control performance in speed tracking and has an excellent ability to handle constraints and predicting system dynamics over the duration of its working status. For example, in Li et al.'s work [16] and Aasim et al.'s work [17], the MPC strategy has been utilized for replacing the PID control for the speed control of a permanent magnet synchronous generator [18], and a comparison of the control performance has been made between the PID controller and MPC controller. The external cycle of PID control and the internal cycle of the MPC control was designed in [17]. Based on a flywheel energy storage system. Apart from the fact that the internal, as well as the external cycles, use PID, the MPC control performance is obviously better than the PID control. Therefore, MPC would have more advantages when applied to wind power control in a wind farm.

A wind farm is composed of multiple wind turbines, and each turbine is an individual control subsystem with local operational constraints. The aggregate power of the wind farm is the sum of the output powers of all turbines, which will be controlled to fulfill a certain control objective, such as providing a smooth power curve or following a reference power trajectory. Therefore, wind power control of the wind farm is an optimal problem of power coordinate control.

By searching in the literature, it is easy to find that the MPC technology has been applied rigorously in the field of wind farm power control and different MPC strategies, such as multispatial-temporal hierarchical MPC [19-21], distributed MPC [22-25], nonlinear MPC [26, 27], adaptive MPC [28-30], etc., have been gradually developed. Thus, it is essential to provide a summary of the application of the MPC technology to wind power control in wind farms. Application of MPC methods in wind control has been summarized in Mahmoud et al.'s work [31], and adaptive control has also been discussed in detail in that article. This paper provides an updated review of the relevant studies from 1997 to 2020, especially the studies conducted in the past five years, and focuses on discussing the commonly used MPC methods and the application scenarios of MPC in detail. It is convenient for researchers to quickly learn about the latest research in their related fields and find issues of interest for further research. For beginners, this review can provide a basic understanding of the usage of MPC technology in wind power control. 
The remainder of this paper has been organized as follows: Section 2 introduces the basic models of wind power generation systems. Section 3 introduces the principle of MPC technology. Section 4 discusses the different application scenarios of MPC wind power prediction and control in wind farms. Section 5 summarizes the main MPC methods applied to wind farm control. The application status of MPC in wind power control in wind farms has been summarized in Section 6 and its future prospect have been presented. Finally, conclusion have been drawn in Section 7.

\section{Wind Turbine System Model}

This section describes some of the basic models used for wind turbines and wind farms.

\subsection{Wind Turbine Model}

In literature, various wind turbine models have been proposed by considering different practical scenarios [32-34]. However, the more detailed physical mode always reduces to the more complex computation task. This subsection mainly introduces the widely adopted nonlinear wind turbine model developed by the National Renewable Energy Laboratory (NREL). The operation principle of a wind turbine is shown in Figure 1:

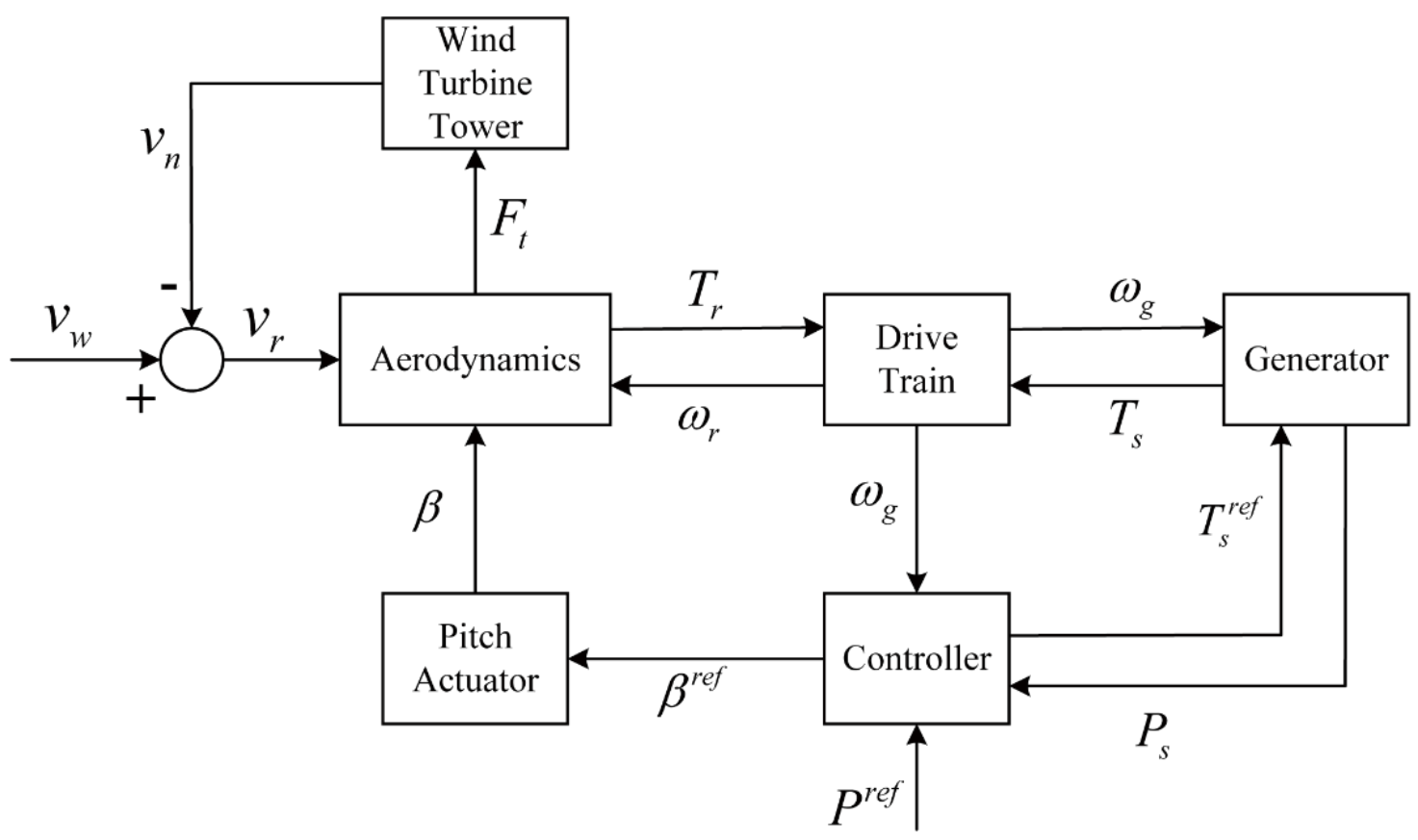

Figure 1 Wind turbine control system of a single wind power generator.

\subsubsection{Aerodynamics}

The aerodynamic model of a wind turbine rotor can be expressed by an aerodynamic torque $\left(T_{r}\right)$ equation and a thrust $\left(F_{t}\right)$ equation, the nonlinear expressions of which are given as follows: 


$$
\left\{\begin{array}{l}
T_{r}=\frac{0.5 \pi \rho R^{2} v_{r}^{3} C_{p}\left(v_{r}, \omega_{r}, \beta\right)}{\omega_{r}} \\
F_{t}=0.5 \pi \rho R^{2} v_{r}^{2} C_{t}\left(v_{r}, \omega_{r}, \beta\right),
\end{array}\right.
$$

where $\rho$ is the air density, $R$ is the blade radius, $v_{r}$ is the wind speed, $\omega_{r}$ is the wind turbine rotor speed, $B$ is the pitch angle, $C_{p}$ is the wind energy utilization factor and $C_{t}$ is the torque factor.

\subsubsection{Drive Train}

The rotor speed, $\omega_{r}$, increases and is transferred through the drive train to the generator shaft, rotating at the speed of $\omega_{g}$, which can be constructed using a two-degrees-of-freedom rotation system. Considering the torsional oscillation caused by the elastic gear meshing and the viscous friction of the rotor and the generator shaft bearings, the model of the transmission system can be expressed as [34]

$$
\left\{\begin{array}{c}
\frac{d \omega_{r}}{d t}=-\frac{B_{r}+B_{d t}}{J_{r}} \omega_{r}+\frac{B_{d t}}{J_{r} N_{g}} \omega_{g}-\frac{K_{d t}}{J_{r}} \theta_{\Delta}+\frac{1}{J_{r}} T_{r} \\
\frac{d \omega_{g}}{d t}=\frac{\eta_{d t} B_{d t}}{N_{g} J_{g}} \omega_{r}-\left(\frac{B_{g}}{J_{g}}+\frac{\eta_{d t} B_{d t}}{J_{g} N_{g}^{2}}\right) \omega_{g}+\frac{\eta_{d t} K_{d t}}{N_{g} J_{g}} \theta_{\Delta}-\frac{1}{J_{g}} T_{g} \\
\frac{d \theta_{\Delta}}{d t}=\omega_{r}-\frac{1}{N_{g}} \omega_{g}
\end{array}\right.
$$

where $J_{r}$ and $J_{g}$ are the inertia of the wind turbine rotor and the generator shafts, respectively, $T_{g}$ is the generator shaft torque, $N_{g}$ is the speed ratio of the drive train, $K_{D T}$ is the torsion stiffness, $B_{d t}$ is the torsion damping, $\vartheta_{\Delta}$ represents the torsional angle of twist of the main shaft, which is defined by $\theta_{\Delta}=\theta_{r}-\frac{\theta_{g}}{N_{g}}, \vartheta_{r}$ and $\vartheta_{g}$ are the rotation angle of rotor and generator shafts, respectively, $B_{r}$ and $B_{g}$ are the coefficients of friction of the gears, and $\eta_{d t}$ is the drive train efficiency in transferring speed.

Furthermore, the shaft torque, $T_{s}$, of a low-speed rotating shaft can be calculated by

$$
\left\{\begin{array}{c}
T_{s}=\frac{N_{g}^{2} J_{g}}{J_{t}} T_{r}+\frac{N_{g} J_{r}}{J_{t}} T_{g}, \\
J_{t}=J_{r}+N_{g}^{2} J_{g} .
\end{array}\right.
$$

\subsubsection{Generator}

At present, there are mainly two types of variable speed and constant frequency wind turbines, namely, the doubly-fed induction generator (DFIG) and the direct-driven permanent magnet synchronous generator (D-PMSG). This paper discusses the DFIG model and the generator model using the direct-quadrature-zero (DQO) rotating coordinate system [35] has been provided, where the flux linkage is taken as the state parameter, and the stator and rotor flux linkage equations are given by 


$$
\left\{\begin{array} { l } 
{ \psi _ { d s } = L _ { s } i _ { d s } + L _ { m } i _ { d r } } \\
{ \psi _ { q s } = L _ { s } i _ { q s } + L _ { m } i _ { q r } } \\
{ \psi _ { d r } = L _ { m } i _ { d s } + L _ { r } i _ { d r } } \\
{ \psi _ { q r } = L _ { m } i _ { q s } + L _ { r } i _ { q r } }
\end{array} \text { and } \left\{\begin{array}{l}
L_{s}=L_{m}+L_{\sigma s} \\
L_{r}=L_{m}+L_{\sigma r} \\
L_{m}=3 M_{s r} / 2
\end{array}\right.\right.
$$

where $L_{\sigma r}$ and $L_{\sigma s}$ are the leakage inductance coefficients of the stator and the rotor, respectively and $M_{s r}$ is the mutual inductance coefficient between stator and rotor.

The voltage relationship between the stator and the rotor is expressed as

$$
\left\{\begin{array}{l}
u_{d s}=\frac{d \psi_{d s}}{d t}-\omega_{1} \psi_{q s}-R_{s} i_{d s} \\
u_{q s}=\frac{d \psi_{q s}}{d t}-\omega_{1} \psi_{d s}-R_{s} i_{q s} \\
u_{d r}=\frac{d \psi_{d r}}{d t}-\omega_{s} \psi_{q r}-R_{s} i_{d r} \\
u_{q r}=\frac{d \psi_{q r}}{d t}-\omega_{s} \psi_{d r}-R_{r} i_{q r}
\end{array}\right.
$$

where $\omega_{1}$ is the synchronous angular velocity and $\omega_{s}=\omega_{1}-\omega_{r}$ is the slip angular velocity.

The active and reactive power in the stator and rotor side $P_{s}, Q_{s}, P_{r}$, and $Q_{r}$, respectively is expressed as

$$
\left\{\begin{array}{l}
P_{s}=u_{d s} i_{d s}+u_{q s} i_{q s} \\
Q_{s}=u_{d s} i_{q s}-u_{q s} i_{d s} \\
P_{r}=u_{d r} i_{d r}+u_{q r} i_{q r} \\
Q_{r}=u_{d r} i_{q r}-u_{q r} i_{d r}
\end{array}\right.
$$

Furthermore, one can derive the active power $P_{e}=P_{s}+P_{r}$ and the reactive power $Q_{e}=Q_{s}+$ $Q_{r}$ of the generator.

The stator torque, $T_{\text {stator, }}$ the rotor torque, $T_{\text {rotor, }}$ and the generator torque, $T_{\text {gen }}$, are expressed as

$$
\left\{\begin{array}{c}
T_{\text {stator }}=\frac{3}{2} p\left(i_{d s} \psi_{q s}-i_{q s} \psi_{d s}\right) \\
T_{\text {rotor }}=\frac{3}{2} p\left(i_{d r} \psi_{q r}-i_{q r} \psi_{d r}\right) \\
T_{\text {gen }}=T_{\text {stator }}+T_{\text {rotor }}
\end{array}\right.
$$

where $p$ represents the pole pairs.

Finally, the generator output power $P_{g e n}=T_{g e n} \omega_{g}$.

\subsubsection{Pitch Angle Controller}

The wind speed range of wind turbines is generally divided into three working stages, namely, the low wind speed stage, the transition stage, and the high wind speed stage. The following principle of the pitch angle control was proposed in Zhao et al.'s work [36]: When the wind speed is lower than the rated wind speed (i.e., the low wind speed stage), a constant value of the pitch angle is maintained in order to follow the maximum power curve and the wind generators run at the optimal tip speed ratio. In other words, the rotor speed is controlled by the generator torque; when 
the rated generator speed is reached (i.e., the transition stage), the wind turbine enters the rated power state, whereas in the high wind speed stage, the power of the wind turbine is larger than the rated power and the rated power is kept constant by adjusting the pitch angle in [35].

By ignoring the dynamic and nonlinear characteristics of the pitch angle controller, a simplified PI control model for the pitch angle can be obtained:

$$
\frac{d \beta}{d t}=\frac{K_{P}}{\tau_{g}}\left(\omega_{f}-N_{g} \omega_{r}\right)-K_{I} \omega_{f}
$$

where $\omega_{f}$ is the equivalent rotor speed by considering the generation efficiency of the generator, $\tau_{g}$ is the time constant, and $K_{P}$ and $K_{l}$ are the control parameters of the variable parameter $\mathrm{PI}$ controller in the pitch angle setting module.

\subsubsection{Linearization}

The aerodynamic torque, $T_{r}$, is a nonlinear function of $v_{w}, \omega_{r}$, and $B$, which often needs to be approximately linearized by the following expression:

$$
T_{r}=\frac{0.5 \pi \rho C_{p}(\beta, \lambda) R^{2} v_{w}^{3}}{\omega_{r}}=\alpha \Delta \omega_{r}+\gamma \Delta v_{r}+\eta \Delta \beta,
$$

where $\Delta \omega_{r}, \Delta v_{r}$, and $\Delta 6$ are the differentials to the selected operating point (also known as the reference value). Then, it is easy to find that

$$
\alpha=\frac{\partial T_{w t}}{\partial \omega_{r}}, \gamma=\frac{\partial T_{w t}}{\partial v_{r}}, \eta=\frac{\partial T_{w t}}{\partial \beta}
$$

Therefore, the linear approximation model of the wind turbine is obtained as follows:

$$
\frac{\mathrm{d} \omega_{\mathrm{r}}}{\mathrm{dt}}=\frac{1}{\mathrm{~J}_{\mathrm{t}}}\left(\alpha \omega_{\mathrm{r}}+\gamma \mathrm{v}_{\mathrm{r}}+\eta \beta+\frac{\mathrm{P}_{\mathrm{WT}} \mathrm{N}_{\mathrm{g}}}{\mu \omega_{\mathrm{g}}} \omega_{\mathrm{r}}-\frac{\mathrm{P}_{\mathrm{WT}}^{\mathrm{ref}} \mathrm{N}_{\mathrm{g}}}{\mu \omega_{\mathrm{g}}}\right) .
$$

\subsubsection{State-Space Equations}

Based on the above description, let $x_{w t}=\left[\omega_{r}, \omega_{g}, \beta\right]^{T}$ be the input variable and $u_{w t}=P_{W T}^{r e f}$ be the control variable. Then, the following state-space equation is obtained:

$$
\dot{x}_{w t}(t)=A_{w t} x_{w t}(t)+B_{w t} u_{w t}(t)+E_{w t}(t)
$$

where the coefficient matrices $A_{w t}, B_{w t}$, and $E_{w t}$ are

$$
A_{w t}=\left[\begin{array}{ccc}
\frac{1}{J_{t}}\left(\alpha+\frac{P_{W T} N_{g}}{\mu \omega_{g}}\right) & 0 & \frac{\eta}{J_{t}} \\
0 & \frac{N_{g}}{\tau_{g}} & -\frac{1}{\tau_{g}} \\
-\frac{N_{g} K_{P}}{\tau_{g}} & \frac{K_{P}}{\tau_{g}}-K_{I} & 0
\end{array}\right],
$$




$$
B_{w t}=\left[\begin{array}{c}
-\frac{N_{g}}{J_{t} \mu \omega_{g}} \\
0 \\
0
\end{array}\right], E_{w t}=\left[\begin{array}{c}
\frac{\gamma v_{r}}{J_{t}} \\
0 \\
0
\end{array}\right]
$$

\subsection{Wind Farm Model}

Suppose that there are $N_{w t}$ wind turbines in a wind farm, the generalized state vector is defined as $x=\left[x_{w t, 1}^{T}, x_{w t, 2}^{T}, \ldots, x_{w t, N_{w t}}^{T}\right]^{T}$, and the system input vector is defined as $u=$ $\left[u_{w t, 1}^{T}, u_{w t, 2}^{T}, \ldots, u_{w t, N_{w t}}^{T}\right]^{T}$. Then, the generalized aggregated wind farm control model is given by

$$
\dot{x}(t)=A x(t)+B u(t)+E,
$$

where

$$
A=\left[\begin{array}{cccc}
A_{w t, 1} & 0 & \cdots & 0 \\
0 & A_{w t, 2} & \cdots & 0 \\
\vdots & \vdots & \ddots & \vdots \\
0 & 0 & \cdots & A_{w t, N_{w t}}
\end{array}\right]
$$

and similarly,

$$
B=\left[\begin{array}{cccc}
B_{w t, 1} & 0 & \cdots & 0 \\
0 & B_{w t, 2} & \cdots & 0 \\
\vdots & \vdots & \ddots & \vdots \\
0 & 0 & \cdots & B_{w t, N_{w t}}
\end{array}\right], E=\left[\begin{array}{c}
E_{w t, 1} \\
E_{w t, 2} \\
\vdots \\
E_{w t, N_{w t}}
\end{array}\right]
$$

Generally, the above continuous-time state-space equation is discretized to be the following discrete-time equation:

$$
x(k+1)=A_{d} x(k)+B_{d} u(k)+E_{d}
$$

where $A_{d}, B_{d}$, and $E_{d}$ are the discrete state matrices.

\section{A Brief Introduction to the MPC Technology}

MPC was developed in the 1960s and is also known as rolling horizon control. It has been inspired by the dynamic matrix control (DMC) and generalized predictive control (GPC) algorithms, which have been widely used in industrial system control. Nowadays, MPC is playing an important role in petroleum, chemical industry, and other fields [37].

As shown in Figure 2, MPC generally includes three steps: prediction model, rolling optimization, and feedback correction. A majority of the currently used prediction models are given by the following state-space equations, obtained by linearizing the nonlinear models and discretizing the continuous-time state equation.

$$
x(k+1)=A x(k)+B u(k)+E
$$


with the initial value $x(0)=x_{0}$, where $x(k) \in \mathbb{R}^{n}$ and $u(k) \in \mathbb{R}^{m}$ represent the state variables and control variables, respectively.

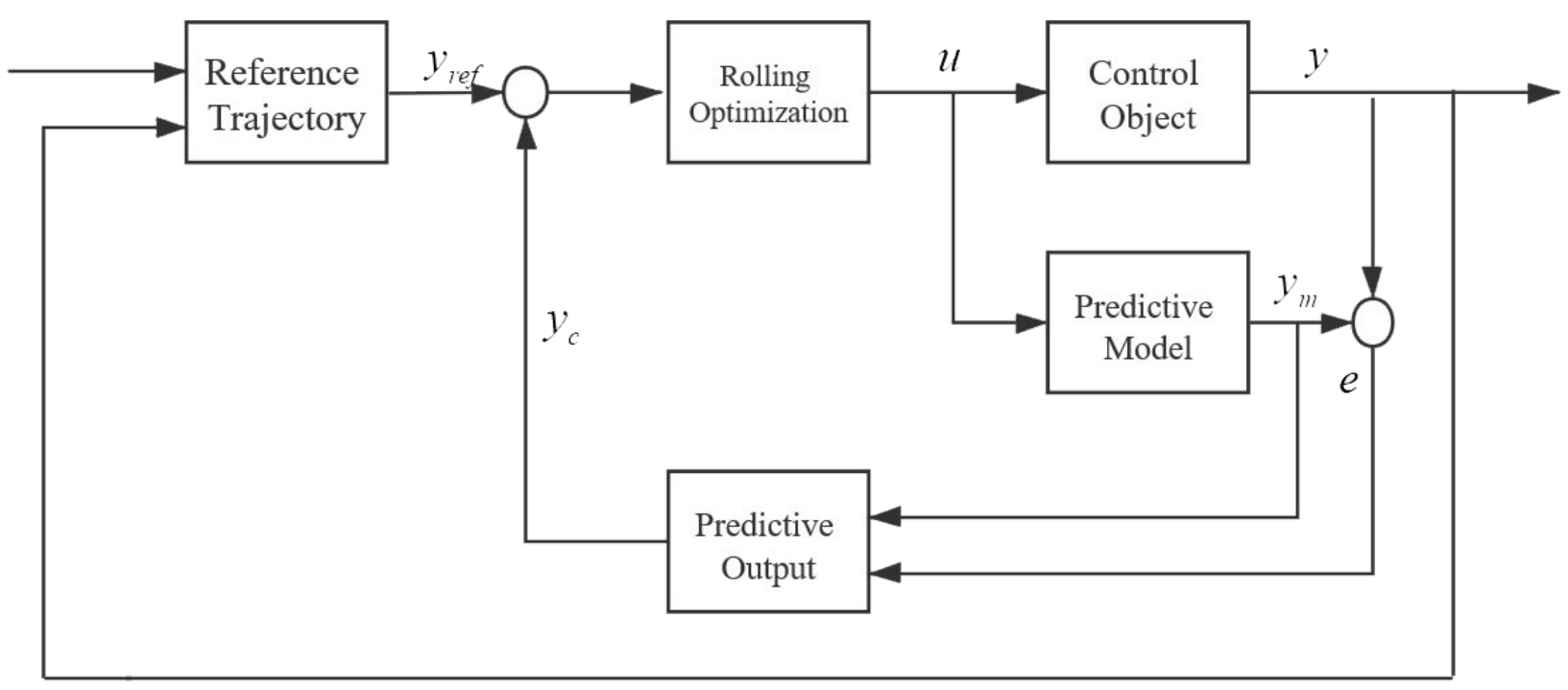

Figure 2 Flowchart of the MPC control strategy for an object.

The MPC control strategy of this model is derived from an open-loop optimization problem,

$$
J_{(p, m)}\left(x_{0}\right)=\min _{u}\left(x^{T}(p) P_{0} x(p)+\sum_{i=0}^{p} x^{T}(i) Q x(i)+\sum_{i=1}^{m-1} u^{T}(i) R u(i)\right)
$$

with the constraint $C x+D u \leq \psi$, where $p \geq m$ and $p, m$ represent the length of the prediction and control range, respectively.

The rolling optimization of MPC mainly involves solving an open-loop control problem within a limited time domain. In this step, the objective function and constraints on the state variables and control variables are set and the control sequence that minimizes the cost function $\left\{u_{(p, m)}^{*}(i\right.$ I $x(k))\}, i=0, \ldots, m-1$ is determined. The first value $u_{(p, m)}^{*}(0 \mid x(k))$ is then inputted as the control variable of the current time to get $x(k+1)=A x(k)+B u_{(p, m)}^{*}(0 \mid x(k))+E$ and the state variable of the next moment is calculated. The closed-loop feedback correction is carried out and the optimization problem and the initial state are updated instantly [38]. Repeating this optimization process can control the output power of the system.

Compared to the traditional control algorithm, the rolling optimization strategy of MPC seeks the local optimal input and reduces online computation. Its feedback correction can collect the state information of the control object in real-time and optimize the control effect in [37]. The MPC repeatedly "predicts + optimizes" at every moment to control the actual output and act on the object being controlled.

As a control method developed for industrial practice, MPC has been able to effectively solve large-scale and multi-objective optimization control problems with the advancement in computing technology, and its robustness and dynamic control capability have also achieved good development. 


\section{Applications of the MPC Technology in The Control of Active and Reactive Power in a Wind} Farm

\subsection{The Status Quo of Applications of the MPC Technology in Active and Reactive Power Control in a Wind Farm}

In the traditional centralized wind power control system, the optimization of active and reactive power is carried out separately. For example, a method of separate optimization of the active and reactive power in wind farms has been put forward in Yang et al.'s work [39] and Martinez-Rojas et al.'s work [40]. Reactive power compensation is processed by the external reactive power compensation equipment, and the active power control of wind turbines, and the regulation of reactive power compensation equipment are completed separately. The flowchart of active and reactive power regulation of wind turbines achieved by PI control is shown in Figure 3.

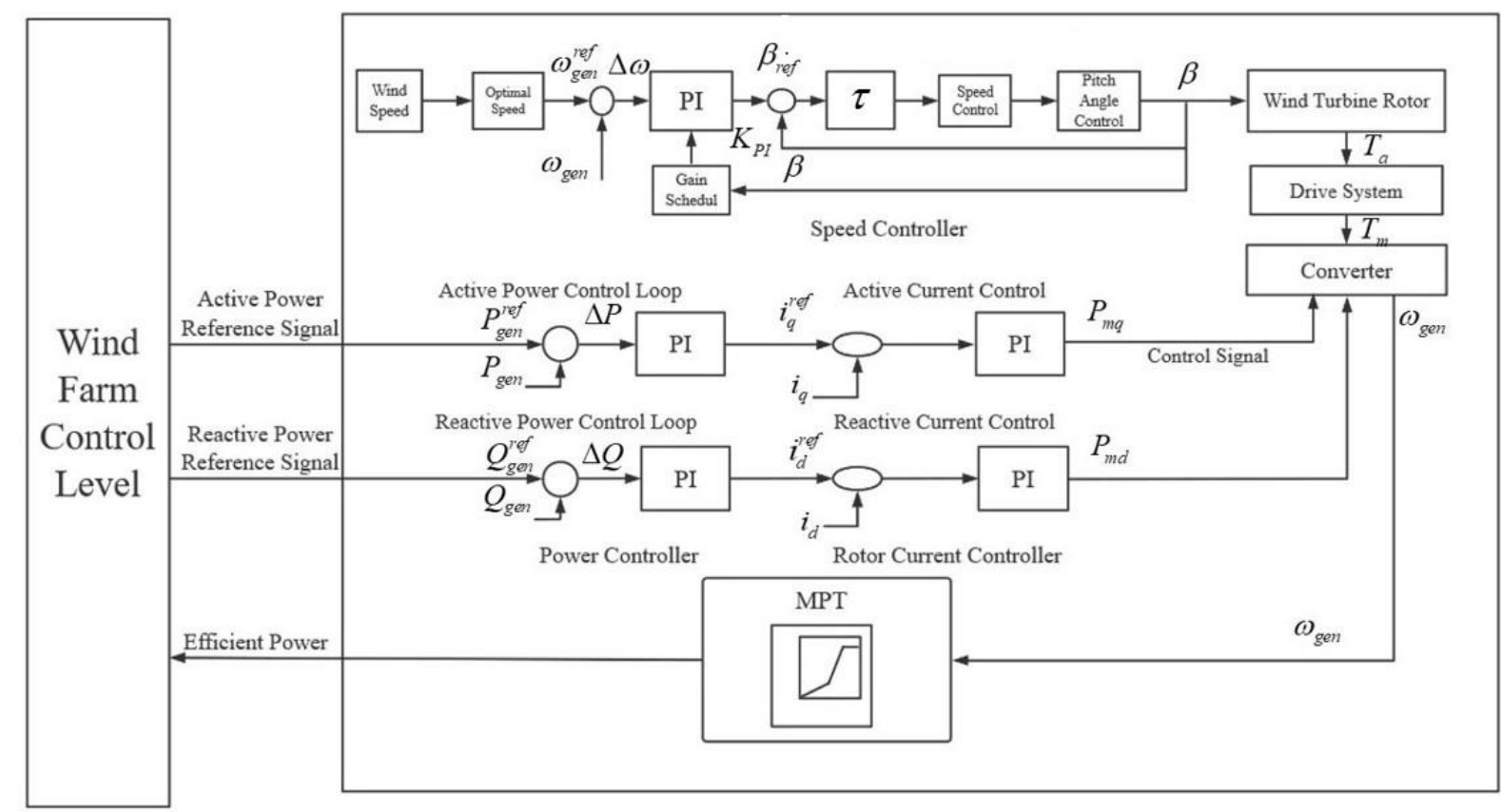

Figure 3 Wind turbine control level with active and reactive loop achieved using the PI control strategy [1].

The control strategy of the active power control loop can be explained as follows: 1) Maximization of wind power: When the wind speed is below the rated wind speed, the objective is to maximize the captured energy by tracking the maximum power coefficient. In this case, the power reference is the available power of the wind turbine. 2) Limitation of wind power: When the wind speed is above the rated wind speed, the power reference is the rated power. Further, the speed controller keeps the generator speed limited to its rated value by adjusting the pitch angle.

\subsubsection{Active Power Control and Fatigue Load Reduction}

For the active power control of a wind farm, the two important factors that need to be considered are tracking the maximum power and minimizing the fatigue load of the wind turbine. In addition, the economic indicators cannot be ignored in the pursuit of wind power efficiency. In 
the process of wind power control, the start-stop operation or frequent action of the wind turbine will increase the fatigue load. When the fatigue strength exceeds the limit, structural damage will be caused to the turbine, which will shorten its service life. Developing methods for coordinating the maximum active power output and reducing the wind turbine fatigue loss is a hot topic worth studying [41].

Harmonizing maximum power generation and reducing the fatigue load is a multi-constraint multi-objective problem. When the MPC method is applied to optimize such a problem, the weighted cost function is usually designed to simultaneously optimize the active power output and reduce the fluctuations of the tower torque. The shaft torque and pitch angle are rotated in order to achieve a balance between the maximization of active power and reduction of the wind turbine fatigue.

The relevant MPC control strategies for wind farms can be found in the literature. Based on the linear multi-objective MPC controller, the authors Liu et al. of Ref. [42] achieved a balance between the average power generation and the longitudinal damping of the tower and solved the contradictory problem of minimizing the fatigue load on the tower while maximizing the power generation. The rain-flow counting method was utilized in Yang et al.'s work [43] to measure the fatigue, and the alternating direction multiplier method (ADMM) was used for designing the distributed model prediction controller to reduce wind turbine fatigue. The sensitivity of the fatigue load of power was defined in Zhao et al.'s work [44] and Liu et al.'s work [45], which provided a simplification of the problem of optimal power distribution. Compared to the distributed model, the global optimal value of a wind farm control can be obtained without additional iterations. Some studies $[46,47]$ investigated the nonlinear MPC and random MPC algorithms for distributing the power to each wind turbine in the wind farm while reducing the mechanical load. The authors of Odgaard et al. [48] designed a multi-objective MPC controller to balance the problems of generating power and reducing the fatigue load of the tower. It has been shown in Evans et al.'s work [49] and Guo et al.'s work [50] that a robust MPC method is better than the general MPC method with respect to minimizing the wind turbine tower load.

At present, almost all active power optimization schemes for wind farms consider the task of reducing the fatigue load as the optimization goal. The MPC technique exhibits excellent handling ability for such a multi-objective multi-constraint problem.

\subsubsection{Reactive Power Control and Voltage/Frequency Regulation}

In the case of reactive power control, the reactive power output of a doubly-fed wind farm mainly comes from the grid-side converter, the stator of the wind generator, and the static synchronous compensator [51], which affects the normal operation after the wind power is connected to the grid. Nowadays, research studies on improving the reactive power regulation capacity of wind farms are gradually increasing [52-54]. Controlling the reactive power plays a pivotal role in stabilizing the system voltage, enhancing the low-voltage crossing capacity of the wind turbine units, accelerating power grid fault recovery, and maintaining the efficient operation of generator units.

Research along this line has shown that voltage control is closely related to the voltage stability of the power systems in [55]. Voltage control is usually realized by means of a static reactive compensator and a static synchronous compensator. An earlier study [56] proposed by Yassami et al. formulated an optimal voltage control scheme based on MPC, which can guarantee voltage 
stability against interferences such as a change in the wind speed. The authors Bigarelli et al. in [57] combined the finite control set model predictive control [58] and pulse width modulator control technology to study the DC bus voltage control for variable speed permanent magnet synchronous generator, which can obtain a high-quality phase current in the steady-state. The authors Guo et al. and Sarkar et al. of Refs. [59,60] proposed an enhanced voltage control strategy based on MPC for offshore wind farms with high-voltage direct-current connections based on voltage source converters.

Frequency regulation generally takes the frequency as a state variable to describe the state space of the wind farm. Some studies $[61,62]$ adopted the distributed hierarchical model predictive control to realize the frequency control problem. A wind farm with an energy storage system was studied as a black start source in an earlier study [20], with the optimal power distribution calculated at the wind farm level to reduce the control error. The authors Huang et al. and Sun et.al in [63, 64] combined active power control with frequency regulation of wind power clusters and adopted the hierarchical distributed model predictive control for multiple space-time coordination.

\subsubsection{Combination of the Active and Reactive Power Control}

It can be seen that adjusting the active and reactive power of wind power generation is helpful for improving the grid-connected operation ability of wind turbines and the stability of the power system. In general, the above power control methods still have some defects, in which the active and reactive power control is considered separately. Some reactive power control strategies are implemented after active power control, and the stability after grid connection cannot be considered while optimizing the active power dispatch. On the other hand, the influence of active power from the wind farm voltage is often ignored. Therefore, coordinating and controlling the active and reactive power is a critical problem that needs to be solved.

In the past decade, a combination of active and reactive power control using the MPC technique has gained considerable attention. The authors Hu et al. of Ref. [65] considered active as well as reactive power, adopted the complex vector model of DFIG in the stator static coordinate system and designed the objective function of the direct control of active and reactive power. The dualobjective constrained optimization model of active and reactive power was obtained, and the reactive limit of DFIG wind farm was studied in Zhao et al.'s work [66] in order to assign the reactive tasks to wind turbines. The impact of active power distribution was considered on the voltage and an MPC-based coordinated voltage control of active and reactive power in wind farms was proposed $[41,67]$. Two control strategies were designed according to the voltage conditions in Guo et al.'s work [68], which significantly improved the voltage stability of the wind farms. Based on the cooperative distributed MPC technique, the active power of wind turbines could be optimized, and the wind farm voltage could be adjusted.

Collaborative control of active and reactive power has exhibited its superiority in maintaining the stability of the wind farm bus voltage, which can greatly improve the ability of a wind farm to cope with interference. At present, research studies are turning to the problems such as communication delay and online model recognition that are encountered in practical applications in wind farms. 


\subsection{Wind Farm Output Power Smoothing Control}

Due to the volatility and uncertainty of wind energy, a wind power control system is also a system having a strong uncertainty, which results in a huge challenge for wind power grid connection. Therefore, the negative impact of the uncertain factors should be eliminated in order to obtain a smooth output power curve.

In practice, wind farms are always equipped with an energy storage system (ESS) to cope with the uncertainty of wind power. An ESS can efficiently compensate for the mismatch between the reference power value and the actual output power of the wind farm via charging and discharging. ESS has been recognized as an effective tool for enhancing the flexibility and controllability of wind farms, which can effectively maintain the safe operation of the grid and suppress the short-term power shocks. Refs. $[63,69]$ considered the MPC optimization problem of the active power of wind farms equipped with ESS. Although the abovementioned methods achieve a stable output of active power, the heterogeneity and energy balance in a battery energy storage system (BESS) is not considered. A novel control structure based on the distributed BESS was designed in Khazaei et al.'s work [70], which not only effectively realizes active and reactive power control, but also solves the abovementioned problems.

There are also discussions and research studies on wind power smoothing control for wind farms without ESS. In Li et al.'s work [71], a combined grid scheduling method considering the loading response based on the stochastic model predictive control was proposed, which makes full use of the flexibility of the load response and reduces the volatility and uncertainty brought by the wind power on the hourly time scale. A clustering method was proposed in Li et al.'s work [72] to supplement the multi-model predictive control algorithm [73] for active power control and a multimodel switching method was utilized for selecting the best sub-model for predictive control at each sampling time, ensuring the smoothness of the active power output. A study on the uncertain wind energy conversion system based on the situational tree stochastic model predictive control was done in Liu et al.'s work [74], in which the Markov jump model was utilized to transform the problem into a deterministic model predictive control problem.

The application of the MPC technology in wind power smoothing control in a wind farm is an upcoming field. Related research on the control based on MPC is gradually increasing with the development of the energy storage technology and demand response technology. Compared to the wind farms without ESS, wind farms assembled with ESS can reduce the load fluctuation of wind turbines and achieve a balance between the power output and the reference value, which is of great significance to keep a steady output power of the wind farms.

\section{Different MPC Methods Applied to Wind Farm Control}

Various MPC methods have been proposed for the power control problem in a wind farm. In Table 1, relevant literatures mentioned in this paper are classified and summarized for the convenience of readers to make it clearer.

\subsection{Hierarchical MPC}

Hierarchical MPC can be regarded as an organic combination of the hierarchical theory and the model predictive control technique. The MPC control model of a large-scale power system provides 
high complexity and is suitable for adopting the decomposing and coordinating hierarchical control method to reduce the solution scale.

In recent years, large-scale wind farms that have been built cover a wide area and are relatively dispersed geographically, of which the wind turbines often have different operating states. In order to track a single wind turbine unit efficiently and control the whole wind farm, the hierarchical MPC method has been widely used. A theoretical description of the hierarchical MPC architecture of a multi-level coordinated active power scheduling mode was provided, which provides a foundation for the power system scheduling control in Zhang et al.'s work [75]. In the practical application process, an earlier study [62] stratified the large-scale independent wind power generation system, where the upper layer adopted iterative distributed control to achieve coordination of power scheduling and the lower layer adopted monitoring and prediction control to achieve economic goals. By the coordination and optimization of various subsystems, the distributed energy can be made to be plug and play. In an earlier study [21], a hierarchical active power control scheme was proposed for wind farms with distributed energy storage systems, which minimize the fatigue load by optimizing the reference value of the active power. Furthermore, the ADMM algorithm with fast convergence speed was adopted to solve the optimization problem, which effectively reduces the amount of computation. The active power scheduling strategy with multiple time scales, which provides good prediction accuracy was studied in Ye et al.'s work [76, 77].

At present, many studies have been performed on the hierarchical MPC method, which has been gradually developed from the temporal and spatial scales of single hierarchical coordination with the joint scheduling model. It is vertically and horizontally layered simultaneously and is based on the idea of "multi-level coordination, cascade refinement". Using this method, the deviation is corrected constantly and the control precision and the ability to balance the power grid are improved. Furthermore, the distributed hierarchical MPC method, which combines the distributed MPC for the whole system with the stratified MPC applied in each subsystem, has also been extensively studied and provides a good solution for dealing with a larger scale wind power system.

\subsection{Multi-objective MPC}

The control design of a wind turbine often involves different operation statuses, which often involves achieving more than one goal, and the goals restrict each other. In this case, the multiobjective MPC method can be used for balancing different or even contradictory objectives. Compared to the general MPC method, the multi-objective MPC strategy has multiple control objectives with different weights and a large number of complex constraints, which also raise the computational load accordingly.

Recently, the Pareto curve has been shown to be effective in determining the weight of multiobjective functions. For example, in order to balance the average power generation and the tower fore-aft fatigue load, the weight factor is obtained by using the gradient of the Pareto curve [48]. In view of the multi-objective function used for optimizing the power and the actuator, the weight factor is selected by imposing a Pareto curve gradient restriction and is applied to the multi-step discrete model in Song et al.'s work [78]. A gain schedule MPC controller for wind turbines was designed in Adegas et al.'s work [79], using the Laguerre function to determine the relevant weight of the cost function and the MPC pitch angle controller to replace the PI control, which reduced the online computing burden. 
An environment and economic dispatch model containing a wind power system was proposed, which can calculate the optimal scheduling policy using the time-varying fuzzy selection mechanism based on the flower pollination algorithm in Yang et al.'s work [80]. An earlier study realized a multiobjective model predictive control of the wind farm wake redirection using a calculation framework and applied the quasi-Newton optimization algorithm to calculate the optimal yaw setting in Van Dijk et al.'s work [81].

Although a multi-objective MPC strategy requires massive calculation, its application to a wind turbine can help in improving the control quality, and its optimization results are consistent with the actual control requirements. In order to simplify the calculation, some studies combine the multi-objective MPC strategy with other forms of MPC strategies, e.g., the multi-objective MPC can be decomposed by the hierarchical method to simplify the problem via a layer-by-layer calculation.

\subsection{Nonlinear MPC}

In practice, the controlled system is generally nonlinear and the results of the linear MPC strategy cannot be utilized anymore. Therefore, research on the nonlinear MPC method has become a hot topic in the field of wind power systems.

In general, there are two methods for solving the nonlinear MPC strategy. First is the precise optimization method, which is based on the detailed high-fidelity model of the system used for online optimization. However, the non-convex optimization problems often need to be solved, which increases the computational complexity for the practical systems. Second is the approximate optimization method involving the approximate processing methods, such as the linearization of the nonlinear systems, which is always utilized for dealing with the optimization of the nonlinear systems. It has the advantage of reducing the computational complexity of the online optimization solution and is consistent with the stability of the equilibrium of the actual controlled system to some extent $[82,83]$.

The approximate optimization method is most widely utilized in studies reported in the literature. $\mathrm{Hu}$ et al.'s work [65] utilized a linear approximation model of the nonlinear DFIG system to investigate the power control problem and the nonlinear terms were ignored. The resulting linear model was too simple. Liu et al.'s work [47] implemented a linear deformation of DFIG system based on the state feedback and carried out the linear MPC using the input-output feedback, which reduced the calculation difficulty considerably. The trajectory local linearization algorithm was adopted in Raach et al.'s work [84] for the nonlinear wind turbines, and a linear and a commercial nonlinear model predictive controller to a baseline controller was proposed. The results of this study showed that the nonlinear model predictive controller could achieve better results compared to the linear model close to the rated wind speed.

In the linearization process, continuous linearization is carried out in the predicted time domain for only a finite number of points, and better control performance can be achieved even if the point is far away from the linearized point. Consequently, the calculation time is increased.

Although the nonlinear characteristics of the wind power systems have been taken into account in the current research studies, the models adopted still cannot accurately describe the practical operational state of the wind power systems. Most of the research on the nonlinear MPC methods is still based on the linear MPC methods and there is no innovative method for detailed models of the system. The nonlinear MPC method using the exact physical models is still an unknown field. It 
not only needs to ensure the high fidelity of the model but also needs to shorten the calculation time as much as possible so that it is constrained within the sampling time of the system, which remains to be further explored [31]. The difficulty of the nonlinear MPC method lies in the complexity of its model and the calculation, and there are still very few relevant research studies. To solve this problem, it is necessary to develop a method for simplifying the model as much as possible while ensuring the authenticity of the system, and at the same time, also seek new powerful computing techniques to support the operation calculation.

\subsection{Distributed MPC}

Distributed MPC is often used for solving the power prediction control problem of large wind farms or multiple wind farms, which can reduce the computing effort of the central controller and speed up the calculation speed of large-scale wind farms. The solution obtained by the distributed MPC is usually the local optimal solution. If the proposed iterative process of searching for local control input is not the global optimal solution, then the distributed optimization technology proposed in Bertsekas et al.'s work [85] can be used to achieve the global optimal solution.

Large-scale wind farms are composed of multiple subsystems, each of which has different control objectives and contributes to the overall control objectives of the whole system. Distributed MPC (DMPC) distributes the online optimization problem of a complex large-scale system to each subsystem and reduces the scale and complexity of the operating system. Therefore, distributed control of wind farms is gradually replacing the centralized control strategy.

For wind farms, the most typical problem is the strong interaction between the wind turbines due to the wake effect, and DMPC is considered to be an effective strategy to deal with this problem. There are two main control modes for power control in a wind farm based on DMPC, namely, the cooperative mode and the non-cooperative mode. In the cooperative mode, each subsystem takes action according to the global performance target [86], whereas in the non-cooperative mode, the dynamic coupling between the subsystems is usually regarded as a disturbance and each subsystem has a locally robust MPC controller [87-89]. However, when the coupling between the subsystems is strong, the non-cooperative DMPC as well as the centralized MPC are not reliable in the practical control process [90].

A study on was done [25] on the active power control in wind farms by using the wake effect model employing DMPC with a focus on the axial induction of the wind turbine. A linear wake model was proposed in Siniscalchiminna et al.'s work [91], which used the cooperative distributed MPC to improve the active power control ability and reduced the communication cost. The problem of coupling between the wind turbines caused by the wake effect was transformed in Gao et al.'s work [92] into a mixed-integer linear programming problem by dividing the wind farm into several uncoupled subsystems, which could improve the elasticity of the system.

To the best of our knowledge, no studies exist on the general method of distributed MPC partition. Some studies have taken the wind speed as the classification basis, e.g., Gionfra et al.'s work [93] put forward a scheme based on DMPC to classify the wind turbines in a wind farm based on their wind speed and designed a power distribution algorithm based on state classification to realize power tracking in wind farms.

As an alternative method between decentralized and centralized control, the distributed control has kept the topology and flexibility of the distributed structure and the centralized closed-loop 
stability [94]. However, in the distributed optimization control strategy, communication delays and communication packet loss have become the major problem for communication which deserves further discussion.

Table 1 A summary of various studies on the different MPC methods.

\begin{tabular}{|c|c|c|}
\hline Reference/Year & Control technique & Objectives \\
\hline$[52] / 2009$ & MPC & $\begin{array}{l}\text { Enhance and maintain power system } \\
\text { transient stability }\end{array}$ \\
\hline$[66] / 2015$ & MPC & $\begin{array}{l}\text { Active and reactive power constrained } \\
\text { optimization model }\end{array}$ \\
\hline$[44] / 2017$ & MPC & Power tracking and minimize fatigue loads \\
\hline$[41] / 2017$ & MPC & Improve the stability of wind farm voltage \\
\hline$[56] / 2018$ & MPC & Guarantee the voltage stability \\
\hline [59]/2018 & MPC & Maintain voltage, reduce the power loss \\
\hline$[95] / 2021$ & MPC & Improve frequency stability of power systems \\
\hline$[31] / 2019$ & Adaptive nonlinear MPC & Reduce computing time \\
\hline [39]/2011 & Centralized MPC & Optimize active and reactive power \\
\hline$[42] / 2019$ & Linear Multi-objective MPC & $\begin{array}{l}\text { Minimize the fatigue load on the tower, } \\
\text { Maximizing power generation }\end{array}$ \\
\hline$[46] / 2017$ & $\begin{array}{l}\text { Nonlinear MPC and Random } \\
\text { MPC }\end{array}$ & Reduce the mechanical load \\
\hline$[48] / 2016$ & Multi-objective MPC & $\begin{array}{l}\text { Balance the power generation, reduce tower } \\
\text { fatigue load }\end{array}$ \\
\hline$[85] / 1997$ & Robust distributed MPC & Reduce grid stability \\
\hline$[49] / 2015$ & Robust MPC & Minimize wind turbine tower load \\
\hline$[51] / 2019$ & Adaptive MPC & Control of reactive power \\
\hline$[58] / 2019$ & Finite control set MPC & Control the smoothness of the active power \\
\hline$[57] / 2020$ & Modulated MPC & $\begin{array}{l}\text { Obtain high quality phase current in steady } \\
\text { state }\end{array}$ \\
\hline$[65] / 2014$ & Direct power control & Eliminate torque oscillations \\
\hline$[68] / 2019$ & $\begin{array}{l}\text { Distributed coordinated active } \\
\text { and reactive power control }\end{array}$ & $\begin{array}{l}\text { Optimal scheduling of active power of wind } \\
\text { turbines, Regulating wind farm voltage }\end{array}$ \\
\hline$[71] / 2019$ & Stochastic MPC & $\begin{array}{l}\text { Reduce the volatility and uncertainty of wind } \\
\text { power }\end{array}$ \\
\hline$[72] / 2020$ & $\begin{array}{l}\text { Adaptive multi-model switching } \\
\text { predictive control }\end{array}$ & $\begin{array}{l}\text { Ensure the smoothness of active power } \\
\text { output }\end{array}$ \\
\hline$[62] / 2019$ & Hierarchical distributed MPC & Realize the distributed energy plug and play \\
\hline$[75] / 2014$ & Hierarchical MPC & Increase forecasting accuracy \\
\hline$[93] / 2016$ & Hierarchical MPC & Track power in wind farm \\
\hline
\end{tabular}




\begin{tabular}{|c|c|c|}
\hline$[76] / 2019$ & Hierarchical MPC & $\begin{array}{l}\text { Improve wind power prediction accuracy and } \\
\text { active power scheduling capability }\end{array}$ \\
\hline$[77] / 2018$ & Hierarchical MPC & Improve the accuracy of predictions \\
\hline$[20] / 2020$ & $\begin{array}{l}\text { Hierarchical MPC, Multi- } \\
\text { objective MPC }\end{array}$ & Reduce grid stability \\
\hline$[21] / 2020$ & $\begin{array}{l}\text { Hierarchical active power } \\
\text { control }\end{array}$ & Minimize fatigue load \\
\hline$[64] / 2019$ & Hierarchical distributed MPC & $\begin{array}{l}\text { Realize wind power cluster participation } \\
\text { system frequency modulation }\end{array}$ \\
\hline$[61] / 2017$ & Distributed hierarchical MPC & $\begin{array}{l}\text { Combine the stochastic programming and } \\
\text { MPC strategy }\end{array}$ \\
\hline$[79] / 2013$ & Multi-objective MPC & Reduce the burden of online computing \\
\hline$[80] / 2017$ & Multi-objective MPC & Reduce the risk of system operation \\
\hline$[81] / 2017$ & Multi-objective MPC & $\begin{array}{l}\text { Optimize power and reduce the mechanical } \\
\text { load }\end{array}$ \\
\hline$[47] / 2014$ & Nonlinear MPC & Reduce the difficulty of calculation \\
\hline$[84] / 2014$ & Nonlinear MPC & Reduce fatigue load \\
\hline$[87] / 2002$ & Distributed MPC & Increase achievable control performance \\
\hline$[86] / 2008$ & Distributed MPC & Enhance AGC stability \\
\hline$[43] / 2017$ & Distributed MPC & Minimize the fatigue load \\
\hline$[25] / 2018$ & Distributed MPC & $\begin{array}{l}\text { Improve the active power control ability, } \\
\text { Reduce the cost of communication }\end{array}$ \\
\hline$[92] / 2018$ & Distributed MPC & Improve the control ability \\
\hline $\begin{array}{l}{[37] / 2018} \\
{[70] / 2019}\end{array}$ & Distributed MPC & Active and reactive power control \\
\hline$[94] / 2020$ & Distributed MPC & Improve the control ability \\
\hline$[91] / 2020$ & Distributed MPC & Improve the elasticity of the system \\
\hline$[22] / 2021$ & Distributed MPC & Maximal wind power generation \\
\hline
\end{tabular}

\section{Overall Research Status and Future Prospects}

Wind power generation technology, as one of the renewable technologies emerging in recent years, has broad development prospects and various techniques are constantly being invented and improved. MPC is a type of optimization algorithm that has good control performance. Based on the principle of its prediction model, a better solution is found for the constrained optimization control problem. Therefore, MPC is increasingly studied with the aim of applying it to the wind power generation system.

By studying the relevant papers on MPC-based wind farm power control, we summarize the research status and characteristics of the application of MPC in wind power generation systems as follows:

1. Many attempts have been made to achieve wind power control using different types of MPC methods. Since the advent of wind power generation technology, researchers have been constantly 
exploring and dealing with the problems of instability and volatility of wind power generation. With the extensive application of the MPC technique in industrial systems, it is gradually applied as a powerful tool for wind power prediction and control in wind farms. In addition, with the development of the MPC technologies such as hierarchical MPC, multi-objective MPC, and distributed MPC, they can be used in different scenarios with different optimization characteristics for different objectives of power control and short-term prediction in wind power generation system.

2. There are many theoretical studies on modeling and analysis of MPC techniques, but very few practical applications incorporating power control in wind farms based on MPC. In practice, most wind farms still use the traditional PID control method because of its simple algorithm and fast response. However, the disadvantages of PID such as, its inability to achieve real-time control for the system with complex dynamic characteristics, cannot be ignored. When the system parameters or load fluctuation have a large change, the control performance will be worsened immediately. Therefore, the practical application of the MPC technique in the wind power generation system is worth exploring, which breaks the strict model structure requirement in the traditional PID control and can predict the further dynamic system behavior (including external disturbance). It can realize optimization of multiple coupled subsystems, can take the unstable factors of the system into account, and make compensation and correction in time. Furthermore, it always establishes a new optimization on the basis of the practical situation in order to achieve optimal control.

3. The wind power control model based on the MPC technique remains to be further improved, and the accuracy of wind power prediction remains to be promoted. Although the nonlinear characteristics of the wind power system have been considered at the moment, the model adopted still cannot describe the variable real operation scenarios accurately. In fact, most research studies use the univariate model, ignoring the impact of the wind direction, varying air density, and other influencing factors, which causes model inaccuracy, poor prediction, and control bias. Certain multidimensional power curve models employing statistical methods, such as the kernel-based multidimensional power curve model, additive multiplicative kernel model [97], kNN-based model, treebased model, and other semi-parametric or nonparametric methods, have been proposed to reach better prediction precision in Ding's work [96]. However, statistical models lack the understanding of physical models. Thus, the topic of utilizing a detailed nonlinear MPC model is still an unknown field.

Wind power optimization and control technology is one of the key issues in renewable power generation, which is a hot topic related to many important areas such as energy and environmental pollution. However, with the development of the times, wind power generation technology has different emphases in different periods. This paper has presented the details of the development of wind power technology combined with the present scenario of the application of the MPC strategy in the key period of wind power control. With the development of wind energy technology, various new theories and methods are emerging and are being applied to wind power control. On the other hand, statistical data are becoming increasingly accurate and specific, which will consequently enable an increasingly scientific, reasonable, and accurate study of wind power generation technology. 


\section{Conclusions}

Owing to the randomness and intermittence of wind power, wind turbines cannot be dispatched or controlled by the dispatch center as other conventional power utilities. Therefore, the prediction and control of wind power become crucial when connecting to the power grids. This article summarizes the application of the MPC method to wind power control in wind farms and compares the advantages and disadvantages of MPC and PID techniques. Different processing methods of MPC, including hierarchical MPC, multi-objective MPC, nonlinear MPC, and distributed MPC have been reviewed and discussed. Furthermore, the key research contents of MPC for active and reactive power control in a wind farm have been analyzed in this article, and an introduction has been given on the combined control model of active and reactive power. The hot topics in active power control, such as reducing the fatigue load, achieving maximum generation, and power stability, have been discussed. Finally, the application problems of MPC in the wind power system have been summarized, and prospects of future development of wind power generation technology have been put forward.

\section{Author Contributions}

C. Li organized the structure of the paper and contributed significantly to the writing of the paper. J. Hu supervised the work, prepared and revised the paper. J. Yu gave the suggestions and supervision. J. Xue undertook to write and revise the paper. R. Yang collected and organized the literature. Y. Fu contributed to the compilation of the wind farm model formula. B. Sun searched the background of MPC and the literatures of wind farm power control problems. All authors discussed the structure and contributed to the final paper.

\section{Funding}

National Nature Science Foundation of China under Grants 61703095, 51977032.

\section{Competing Interests}

The authors declare that they have no known competing financial interests or personal relationships that could have appeared to influence the work reported in this paper.

\section{References}

1. Hansen AD, Sørensen P, Iov F, Blaabjerg F. Centralised power control of wind farm with doubly fed induction generators. Renew Energy. 2005; 31: 935-951.

2. Mei F, Pal B. Modal analysis of grid-connected doubly fed induction generators. IEEE Trans Energy Convers. 2007; 22: 728-736.

3. Jafarnejadsani $\mathrm{H}$, Pieper J, Ehlers J. Adaptive control of a variable-speed variable-pitch wind turbine using radial-basis function neural network. IEEE Trans Control Syst Technol. 2013; 21: 2264-2272.

4. Ebrahimi FM, Khayatiyan A, Farjah E. A novel optimizing power control strategy for centralized wind farm control system. Renew Energy. 2016; 86: 399-408. 
5. Bahadur TK, Jayasawal K. Pitch control scheme for rapid active power control of a PMSG-based wind power plant. IEEE Trans Ind Appl. 2020; 56: 6756-6766.

6. Luo HC, Hu ZC, Zhang HC, Chen HM. Coordinated active power control strategy for deloaded wind turbines to improve regulation performance in AGC. IEEE Trans Power Syst. 2018; 34: 98 108.

7. Sánchez JC, Marjanovic O, Barnes M, Green PR. Secondary model predictive control architecture for VSC-HVDC networks interfacing wind power. IEEE Trans Power Deliv. 2020; 35: 2329-2341.

8. Wu QW, Akhmatov V, Takarics T. Coordinated voltage and reactive power control of offshore HVAC meshed grid and wind power. IET Renew Power Gener. 2020; 14: 3045-3057.

9. Liu XJ, Zhang Y, Lee KY. Coordinated distributed MPC for load frequency control of power system with wind farms. IEEE Trans Ind Electron. 2017; 64: 5140-5150.

10. Gaur S, Elias S, Höbbel T, Matsagar VA, Thiele K. Tuned mass dampers in wind response control of wind turbine with soil-structure interaction. Soil Dyn Earthq Eng. 2020; 132. DOI: 10.1016/j.soildyn.2020.106071.

11. Campione G, Monaco A, Cannella F. Flexural test on a full-scale 60-kW wind turbine tower telescopic steel pipe. Pract Period Struct Des Constr. 2019; 24. DOI: 10.1061/(ASCE)SC.19435576.0000433.

12. Mendes P, Correia JA, Mourão A, Pereira R, Fantuzzi N, De Jesus A, et al. Fatigue assessments of a jacket-type offshore structure based on static and dynamic analyses. Pract Period Struct Des Constr. 2021; 26. DOI: 10.1061/\%28ASCE\%29SC.1943-5576.0000533.

13. Sigurðsson GÖ, Rupakhety R, Rahimi SE, Olafsson S. Effect of pulse-like near-fault ground motions on utility-scale land-based wind turbines. Bull Earthq Eng. 2020; 18: 953-968.

14. Yao Q, Hu Y, Deng H, Luo ZL, Liu JZ. Two-degree-of-freedom active power control of megawatt wind turbine considering fatigue load optimization. Renew Energy. 2020; 162: 2096-2112.

15. Wang XZ, Du W. Development overview of model predictive control. Automation Instrum. 1999; 4: 3-5. doi: 10.14016/j.cnki.1001-9227.1999.04.002.

16. Li L, Zhang DY. Model predictive control for wind farm integration through VSC-HVDC. Proceedings of the 13th IEEE Conference on Industrial Electronics and Applications (ICIEA); 2018 May 31-June 2; Wuhan, China.

17. Aasim, Singh SN, Mohapatra A. Active power regulation by MPC based flywheel energy storage system. Adv Energy Power Syst. 2018; 508: 57-71.

18. Mousa HH, Youssef AR, Mohamed EE. Model predictive speed control of five phase permanent magnet synchronous generator based wind generation system via wind speed estimation. Int Trans Electr Energy Syst. 2019; 29: 1-16.

19. Huang S, Wu QW, Bao WY, Hatziargyriou ND, Ding L, Rong F. Hierarchical optimal control for synthetic inertial response of wind farm based on alternating direction method of multipliers. IEEE Trans Sustain Energy. 2021; 12: 25-35.

20. Liu WP, Liu YT. Hierarchical model predictive control of wind farm with energy storage system for frequency regulation during black-start. Int J Electr Power Energy Syst. 2020: 119. DOI: 10.1016/j.ijepes.2020.105893.

21. Huang S, Wu QW, Guo YF, Rong F. Hierarchical active power control of DFIG-based wind farm with distributed energy storage systems based on ADMM. IEEE Trans Sustain Energy. 2019; 11: 1528-1538. 
22. Yin XX, Zhao XW. Deep neural learning based distributed predictive control for offshore wind farm using high-fidelity LES data. IEEE Trans Ind Electron. 2020; 68: 3251-3261.

23. Deng JX, Song YA, Gong YS, Chen WM. Hierarchical distributed MPC for optimal active power control of DFIG wind farms. Proceedings of the IEEE/IAS Industrial and Commercial Power System Asia (I\&CPS Asia); 2020 July 13-15; Weihai, China.

24. Yan YJ, Zhang Y, Liu XJ. Distributed MPC strategy with application to AGC in the presence of variable speed wind turbine. Proceedings of the 34th Chinese Control Conference (CCC); 2015 July 28-30; Hangzhou, China.

25. Bay CJ, Annoni J, Taylor T, Pao L, Johnson K. Active power control for wind farms using distributed model predictive control and nearest neighbor communication. Proceedings of the 2018 Annual American Control Conference (ACC); 2018 June 27-29; Milwaukee, WI, USA.

26. Kou P, Liang D, Yu L, Gao L. Nonlinear model predictive control of wind farm for system frequency support. IEEE Trans Power Syst. 2019; 34: 3547-3561.

27. Curtis Saunders D, Marshall JS, Hines PD. The effect of timescales on wind farm power variability with nonlinear model predictive control. Wind Energy. 2017; 20: 1891-1908.

28. Rafiee Z, Heydari R, Rafiee M, Aghamohammadi MR, Rodriguez J, Blaabjerg F. Adaptive model predictive control of DFIG-based wind farm: A model-free control approach. Proceedings of the IEEE 21st Workshop on Control and Modeling for Power Electronics (COMPEL); 2020 November 9-12; Aalborg, Denmark.

29. Wei J, Cao YJ, Wu QW, Li CB, Huang S, Zhou B, et al. Coordinated droop control and adaptive model predictive control for enhancing HVRT and post-event recovery of large-scale wind farm. IEEE Trans Sustain Energy. 2021; 12: 1549-1560.

30. Yang DY, Wang B, Cai GW, Ma J, Tian J, Chen Z, et al. Inertia-adaptive model predictive controlbased load frequency control for interconnected power systems with wind power. IET Gener Transm Distrib; 14: 5029-5036.

31. Mahmoud MS, Oyedeji MO. Adaptive and predictive control strategies for wind turbine systems: A survey. IEEE/CAA J Autom Sin. 2019; 6: 364-378.

32. Santoso S, Le HT. Fundamental time domain wind turbine models for wind power studies. Renew Energy. 2007; 32: 2436-2452.

33. Habibi H, Nohooji HR, Howard I. Power maximization of variable-speed variable-pitch wind turbines using passive adaptive neural fault tolerant control. Front Mech Eng. 2017; 12: 377388.

34. Habibi H, Howard I, Simani S. Reliability improvement of wind turbine power generation using model-based fault detection and fault tolerant control: A review. Renew Energy. 2019; 135: 877-896.

35. Xiang K. The study of wind power generation system simulation based on matlab. Beijing; North China Electric Power University; 2007.

36. Zhao HR, Wu QW, Guo QL, Sun HB, Xue YS. Distributed model predictive control of a wind farm for optimal active power controlpart I: Clustering-based wind turbine model linearization. IEEE Trans Sustain Energy. 2015; 6: 831-839.

37. Luo ZX. Collaborative scheduling of active and reactive power in wind farms based on MPC. Chongqing; Chongqing University; 2018.

38. Morari M, Lee JH. Model predictive control: Past, present and future. Comput Chem Eng. 1999; 23: 667-682. 
39. Yang H, Liang HF, Li GY. A coordinated voltage control strategy for wind farm containing doubly fed induction generators. Power Syst Technol. 2011; 35: 121-126.

40. Martinez-Rojas $M$, Sumper A, Gomis-Bellmunt $O$, Sudrià-Andreu A. Reactive power dispatch in wind farms using particle swarm optimization technique and feasible solutions search. Appl Energy. 2011; 88: 4678-4686.

41. Zhao HR, Wu QW, Wang JH, Liu ZX, Shahidehpour M, Xue YS. Combined active and reactive power control of wind farms based on model predictive control. IEEE Trans Energy Convers. 2017; 32: 1177-1187.

42. Liu XJ, Wu Q, Kong XB. Economic model predictive control for wind turbine. Proceedings of the Chinese Control Conference (CCC); 2019 July 27-30; Guangzhou, China.

43. Yang NN. The research of distributed model predictive control for wind farms. Beijing: North China Electric Power University (Beijing); 2017.

44. Zhao HR, Wu QW, Huang SJ, Shahidehpour M, Guo QL, Sun HB. Fatigue load sensitivity-based optimal active power dispatch for wind farms. IEEE Trans Sustain Energy. 2017; 8: 1247-1259.

45. Liu YM, Wang YW, Wang XD, Zhu JS, Lio WH. Active power dispatch for supporting grid frequency regulation in wind farms considering fatigue load. Energies. 2019; 12: 1508.

46. Riverso S, Manciniand S, Sarzo F, Ferrari-Trecate G. Model predictive controllers for reduction of mechanical fatigue in wind farms. IEEE Trans Control Syst Technol. 2017; 25: 535-549.

47. Liu XJ, Kong XB. Nonlinear model predictive control for DFIG-based wind power generation. IEEE Trans Autom Sci Eng. 2014; 11: 1046-1055.

48. Odgaard PF, Larsen LF, Wisniewski R, Hovgaard TG. On using pareto optimality to tune a linear model predictive controller for wind turbines. Renew Energy. 2016; 87: 884-891.

49. Evans MA, Cannon M, Kouvaritakis B. Robust MPC tower damping for variable speed wind turbines. IEEE Trans Control Syst Technol. 2015; 23: 290-296.

50. Guo TT, Liu YB, Zhao JB, Zhu YW, Liu JY. A dynamic wavelet-based robust wind power smoothing approach using hybrid energy storage system. Int J Electr Power Energy Syst. 2020; 116. DOI: 10.1016/j.ijepes.2019.105579.

51. Xie M, Jia YP, Hou JX, Fu B, Gong M. Research on low-voltage crossing control mechanism of wind farm based on adaptive model prediction. Renew Energy. 2019; 37: 1152-1158.

52. Nguyen TT, Wagh SR. Model predictive control of facts devices for power system transient stability. Proceedings of the Transmission and Distribution Conference and Exposition: Asia and Pacific; 2009 October 26-30; Seoul, South Korea.

53. Zhao JJ, Li X, Hao JT, Lu JP. Reactive power control of wind farm made up with doubly fed induction generators in distribution system. Electr Power Syst Res. 2010; 80: 698-706.

54. Li J, Wang N, Zhou D, Hu WH, Huang Q, Chen Z, et al. Optimal reactive power dispatch of permanent magnet synchronous generator-based wind farm considering levelised production cost minimisation. Renew Energy. 2020; 145: 1-12.

55. Van Cutsem T, Vournas C. Voltage stability of electric power systems. Heidelberg, Germany: Springer Science \& Business Media; 2007.

56. Yassami H, Rabiee A, Jalilvand A, Bayat F. Model predictive control scheme for coordinated voltage control of power systems at the presence of volatile wind power generation. IET Gener Transm Distrib. 2018; 12: 1922-1928. 
57. Bigarelli L, Benedetto MD, Lidozzi A, Solero L, Odhano SA, Zanchetta P. PWM-based optimal model predictive control for variable speed generating units. IEEE Trans Ind Appl. 2020; 56: 541550.

58. Nasiri MR, Farhangi S, Rodriguez J. Model predictive control of a multilevel CHB statcom in wind farm application using diophantine equations. IEEE Trans Ind Electron. 2019; 66: 1213-1223.

59. Guo YF, Gao HL, Wu QW, Zhao HR, Ostergaard J, Shahidehpour M. Enhanced voltage control of VSC-HVDC-connected offshore wind farms based on model predictive control. IEEE Trans Sustain Energy. 2018; 9: 474-487.

60. Sarkar M, Souxes T, Hansen AD, Sørensen PE, Vournas CD. Enhanced wind power plant control strategy during stressed voltage conditions. IEEE Access. 2020; 8: 120025-120035.

61. Sun BH, Tang Y, Zhong WZ, Ye L, Li Z, Lan HB. Multi-area interconnected power system advanced frequency control strategy considering large scale wind power cluster integration based on DMPC. Proc CSEE. 2017; 37: 6291-6302.

62. Kong XB, Liu XJ, Ma LL, Lee KY. Hierarchical distributed model predictive control of standalone wind/solar/battery power system. IEEE Trans Syst Man Cybern Syst. 2019; 49: 1570-1581.

63. Huang S, Wu QW, Guo YF, Rong F. Optimal active power control based on MPC for DFIG-based wind farm equipped with distributed energy storage systems. Int J Electr Power Energy Syst. 2019; 113: 154-163.

64. Sun BH, Tang $\mathrm{Y}, \mathrm{Ye} \mathrm{L}$, Zhong $\mathrm{WZ}$, ZHANG CH, CHEN CY, et al. Integrated frequency control strategy for wind power cluster with multiple temporal-spatial scale coordination based on $\mathrm{H}$ DMPC. Proc CSEE. 2019; 39: 155-167.

65. Hu JF, Zhu JG, Dorrell DG. Model-predictive direct power control of doubly-fed induction generators under unbalanced grid voltage conditions in wind energy applications. IET Renew Power Gener. 2014; 8: 687-695.

66. Zhao HR, Wu QW, Guo QL, Sun HB, Huang SJ, Xue YS. Coordinated voltage control of a wind farm based on model predictive control. IEEE Trans Energy Convers. 2016; 7: 1440-1451.

67. Zhang LF. Research on wind turbines in wind farm of active power and reactive power coordinated optimization dispatching. Beijing: North China Electric Power University; 2015.

68. Guo YF, Gao HL, Wu QW, Østergaard J, Yu DC, Shahidehpour M. Distributed coordinated active and reactive power control of wind farms based on model predictive control. Int J Electr Power Energy Syst. 2019; 104: 78-88.

69. Zhao HR, Wu QW, Guo QL, Sun HB, Xue YS. Optimal active power control of a wind farm equipped with energy storage system based on distributed model predictive control. IET Gener Transm Distrib. 2016; 10: 669-677.

70. Khazaei J, Nguyen DH. Distributed consensus for output power regulation of DFIGs with on-site energy storage. IEEE Trans Energy Convers. 2019; 34: 1043-1051.

71. Li H, Wang ZD, Wang X. Peng CY, Hou YH, Yin WQ. Coordinated dispatch of power grid based on stochastic model predictive control. Electr Power Autom Equip. 2019; 39: 30-36.

72. Li HW, Ren KD, Li SB, Dong HY. Adaptive multi-model switching predictive active power control scheme for wind generator system. Energies. 2020; 13: 1329.

73. Özkan L, Kothare MV. Stability analysis of a multi-model predictive control algorithm with application to control of chemical reactors. J Process Control. 2006; 16: 81-90.

74. Liu M, Zou JX, Peng C, Xie YC, Li MW. Active power control for wind farms based on MPC combined with state classification. IFAC-PapersOnLine. 2017; 50: 2137-2144. 
75. Zhang BM, Chen JH, Wu WC. A hierarchical model predictive control method of active power for accommodating large-scale wind power integration. Autom Electr Power Syst. 2014; 38: 614.

76. Ye L, Zhang CH, Tang Y, Zhong WZ, Zhao YN, Lu P, et al. Hierarchical model predictive control strategy based on dynamic active power dispatch for wind power cluster integration. IEEE Trans Power Syst. 2019; 34: 4617-4629.

77. Ye L, Zhang CH, Tang Y, Sun BH, Zhong WZ, Lan HB, et al. Active power stratification predictive control approach for wind power cluster with multiple temporal and spatial scales coordination. Proc CSEE. 2018; 38: 3767-3780.

78. Song DR, Li QA, Cai ZL, Li L, Yang J, Su M, et al. Model predictive control using multi-step prediction model for electrical yaw system of horizontal-axis wind turbines. IEEE Trans Sustain Energy. 2019; 10: 2084-2093.

79. Adegas FD, Wisniewski R, Larsen LF. Gain-scheduled model predictive control of wind turbines using laguerre functions. Proceedings of the American Control Conference; 2013 June 17-19; Washington, DC, USA.

80. Yang JR, Wang XC, Sui LT, Liu XZ, Luo XF. Multi-objective optimal scheduling of wind integrated power systems with hybrid intelligent algorithm. Power Syst Prot Control. 2017; 45: 21-27.

81. Van Dijk MT, Van Wingerden JW, Ashuri T, Li YY. Wind farm multi-objective wake redirection for optimizing power production and loads. Energy. 2017; 121: 561-569.

82. Kong XB. Research on nolinear model predictive control and its application in power generation control. Beijing: North China Electric Power University (Beijing); 2014.

83. Schlipf D, Schlipf DJ, Kuhn M. Nonlinear model predictive control of wind turbines using LIDAR. Wind Energy. 2013; 16: 1107-1129.

84. Raach S, Schlipf D, Sandner F, Matha D, Cheng PW. Nonlinear model predictive control of floating wind turbines with individual pitch control. Proceedings of the American Control Conference; 2014 June 4-6; Portland, OR, USA.

85. Bertsekas DP, Tsitsiklis JN. Parallel and distributed computation: Numerical methods. Englewood Cliffs, NJ: Prentice hall; 1997.

86. Venkat N, Hiskens IA, Rawlings JB, Wright SJ. Distributed MPC strategies with application to power system automatic generation control. IEEE Trans Control Syst Technol. 2008; 16: 11921206.

87. Farina $M$, Scattolini R. Distributed predictive control: A non-cooperative algorithm with neighbor-to-neighbor communication for linear systems. Automatica. 2012; 48: 1088-1096.

88. Othman AM, El-Fergany AA. Design of robust model predictive controllers for frequency and voltage loops of interconnected power systems including wind farm and energy storage system. IET Gener Transm Distrib. 2018; 12: 4276-4283.

89. Xie YY, Guo WQ, Wu QW, Wang K. Robust MPC-based bidding strategy for wind storage systems in real-time energy and regulation markets. Int J Electr Power Energy Syst. 2021; 124. DOI: 10.1016/j.ijepes.2020.106361.

90. Cui H, Jacobsen EW. Performance limitations in decentralized control. J Process Control. 2002; 12: 485-494.

91. Siniscalchiminna S, Bianchi FD, Ocampomartinez C, Dominguezgarcia JL, De Schutter B. A noncentralized predictive control strategy for wind farm active power control: A wake-based partitioning approach. Renew Energy. 2020; 150: 656-669. 
92. Gao BT, Hu ZY, Zhang L, Yang ZC. De-loading optimal control of wind farm based on wake effect. Renew Energy. 2018; 36: 117-125.

93. Gionfra N, Siguerdidjane H, Sandou G, Faille D. Hierarchical control of a wind farm for wake interaction minimization. IFAC-PapersOnLine. 2016; 49: 330-335.

94. Stewart BT, Venkat AN, Rawlings JB, Wright SJ, Pannocchia G. Cooperative distributed model predictive control. Syst Control Lett. 2010; 59: 460-469.

95. Ademola-Idowu A, Zhang BS. Frequency stability using MPC-based inverter power control in low-inertia power systems. IEEE Trans Power Syst. 2021; 36: 1628-1637.

96. Ding Y. Data science for wind energy. Boca Raton: CRC Press; 2019.

97. Lee G, Ding Y, Genton MG, Xie L. Power curve estimation with multivariate environmental factors for inland and offshore wind farms. J Am Stat Assoc. 2015; 110: 56-67.

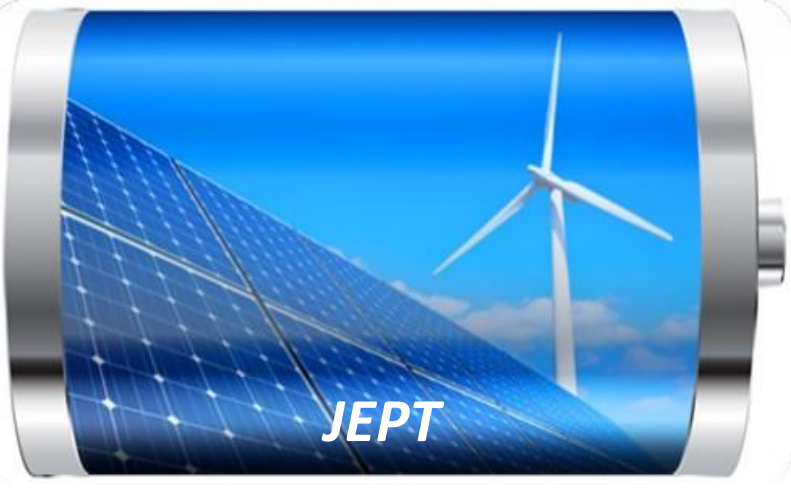

Enjoy JEPT by:

1. Submitting a manuscript

2. Joining in volunteer reviewer bank

3. Joining Editorial Board

4. Guest editing a special issue

For more details, please visit:

http://www.lidsen.com/journal/jept 